ArtefaCToS. Revista de estudios de la ciencia y la tecnología

eISSN: 1989-3612

Vol. 7, No. 1 (2018), 2a Época, 155-173

DOI: http://dx.doi.org/10.14201/art201871155173

\title{
Miedo y riesgo tecnológico en el catastrofismo filosófico de Jean Pierre Dupuy y Paul Virilio
}

\section{Fear and technological risk in the philosophical catastrophism of Jean Pierre Dupuy and Paul Virilio}

Miguel ZAPATA CLAVERÍA

Universidad Nacional Autónoma de México

miguelzapataclaveria@hotmail.com

Recibido: 10/01/2018. Revisado: 18/01/2018. Aceptado: 25/01/2018

\section{Resumen}

En este trabajo se presentarán y evaluarán las tesis filosóficas de Jean Pierre Dupuy y Paul Virilio sobre el miedo que generan las consecuencias negativas derivadas de la puesta en marcha de algunos de los sistemas tecnológicos que dan forma al mundo contemporáneo. Si bien ambos autores ponen el énfasis en el potencial catastrófico de la tecnología, sus opiniones difieren al evaluar el papel del miedo como elemento obstaculizador o posibilitador de lo que a su juicio son las consecuencias devastadoras de la tecnificación del mundo. Mientras Dupuy asume la heurística del temor de Hans Jonas y, por tanto, comprende el miedo como una herramienta adecuada para evitar los peores futuros escenarios que podamos imaginar; Virilio desarrolla una crítica al control social que se ejerce mediante la detonación de temores colectivos que son propagados a través de las tecnologías de la información y la comunicación. Además, sus planteamientos también difieren en lo que respecta a la evaluación de los riesgos, pues si Dupuy recela de la que llevan a cabo los expertos mediante un cálculo de costo/beneficio; Virilio considera que la evaluación social está afectada por miedos irracionales que impiden detectar las verdaderas causas de los problemas tecnológicos.

Palabras clave: accidentes; catástrofes; expertos; sistemas tecnológicos; temor. 


\begin{abstract}
In this work we will present and evaluate the philosophical thesis of Jean Pierre Dupuy and Paul Virilio about the fear generated by the negative consequences derived from the implementation of some of the technological systems that shape the contemporany world. While both authors place emphasis on the catastrophic potential of technology, their opinions differ in assesing the role of fear as an impeding or enabling element in the undesirable and devastating consequences of the global technification. While Dupuy assumes the fear heuristic of Hans Jonas and, therefore, understands fear as an adequate tool to avoid the worst future scenarios we can imagine; Virilio, on the other hand, develops a critique of social control exercised through the detonation of collective fears that are propagated through information and communication technologies. In addition, their approaches differ with regard to the evaluation of risks; because, if Dupuy is suspicious of the one carried out by the experts through a cost/benefit calculation, Virilio believes that social evaluation is affected by irrational fears that prevent the true causes of technological problems from being detected.
\end{abstract}

Keywords: Accidents; Catastrophes; Experts; Technological Systems; Aprehensiveness.

- ¿A qué se debe, Alfonse, que las personas decentes, bienintencionadas y responsables, se sientan intrigadas ante la catástrofe cuando la contemplan en la televisión?-le dije.

[...]

- Porque padecemos marchitamiento cerebral. Necesitamos una catástrofe de vez en cuando para interrumpir el incesante bombardeo de información.

[...]

- El flujo es constante-dijo Alfonse-. Palabras, imágenes, cifras, hechos, gráficos, estadísticas, motas, ondas, partículas. Tan sólo las catástrofes logran captar nuestra atención. Las deseamos, las necesitamos, dependemos de ellas. Siempre y cuando sucedan en otro lugar.

Don DeLillo. Ruido de Fondo

\author{
CATASTROFISTA? \\ claro que sí \\ pero MODERADO!
}

Nicanor Parra, Ecopoemas

\title{
Introducción: tecnología y catástrofe
}

La filosofía del s. XX estuvo marcada por una visión pesimista de la tecnología generada, tanto por la constatación de un progresivo abandono de las formas de vida tradicionales asociado a los nuevos contextos industriales y tecnológicos, como por el miedo provocado por el desarrollo de armas con la capacidad de aca- 
bar con una gran cantidad de vidas humanas en una sola operación relámpago. ${ }^{1}$ Entre los pensadores más críticos con el mundo tecnológico se encuentran los discípulos de Heidegger, Hans Jonas y Günther Anders, quienes sistematizaron su obra filosófica a partir de la idea de que la tecnología constituye una fuerza deshumanizadora que pone en peligro las condiciones de una existencia auténticamente humana en la Tierra. Desde otra perspectiva, pero con un talante igual de pesimista, la escuela de Frankfurt (Adorno y Horkheimer, 1998; Horkheimer, 2002) pensó la tecnología como manifestación de una forma de racionalidad característica de la modernidad, la instrumental, orientada hacia el dominio de la naturaleza y los hombres. La relevancia e influencia de estas dos de las líneas de pensamiento sobre la técnica más representativas del s. XX pone de manifiesto el carácter tecnofóbico con que abordó la filosofía el ámbito de la praxis destinado a la transformación del mundo.

Actualmente, lejos del asombro que produjo la capacidad mortífera de la nueva instrumentación bélica, anclados en una modernidad desarraigada de la tradición y atemperado el riesgo de aniquilación nuclear que supuso la fragmentación mundial en dos bloques durante la Guerra Fría, la filosofía no ha perdido el interés por los peligros de la tecnología que llamaron con tanta fuerza la atención de los autores mencionados. La influencia de Primavera Silenciosa (Carson, 1962), en la que se advertía sobre los dańos que estaba provocando el uso de pesticidas en las formas de vida silvestres, la proliferación de grupos críticos con la propagación al ambiente de diferentes sustancias químicas dañinas para la salud o los ecosistemas; accidentes nucleares como los de Three Mile Islands, Chernobil o Fukushima; estudios, como los de Molina, que mostraron una relación causal entre el aumento del agujero de la capa de ozono y la propagación a la atmósfera de compuestos clorofluorocarbonados (Olive, 2011, 47-59); o el desarrollo de tecnologías de modificación y transferencia genética que han revolucionado la agricultura y la medicina abriendo profundos debates sobre los beneficios y riesgos de la intervención tecnológica de los organismos biológicos, son una parte del conjunto de fenómenos técnicos que actualmente nutren una reflexión filosófica sobre la tecnología de corte apocalíptico. Dos de los autores que de manera más audaz han tratado el tema, Dupuy y Virilio, han dirigido su atención hacia el potencial catastrófico de la técnica contemporánea aportando sugerentes y contrapuestas tesis en relación al papel que juega el miedo en un contexto de creciente percepción del riesgo tecnológico. La comparación entre las ideas de ambos autores nos aportará algunas claves para comprender por qué el miedo generado por las imágenes de las catástrofes puede ser considerado, o bien la base

\footnotetext{
${ }^{1}$ Mitcham (1989) habla de dos tradiciones en la filosofía de la tecnología. La primera, desarrollada por ingenieros como Ernst Kapp y Friedrich Dessauer, trató el tema de la técnica desde la óptica optimista que imprime la confianza en el progreso. La segunda tradición, surgida de las humanidades, hizo una valoración del fenómeno técnico mucho más negativa. La tradición que se indica en el texto es esta última, ya que sus protagonistas tuvieron mucho más peso en la filosofía de la época que los ingenieros.
} 
sobre la que construir una reflexión que nos permita evitar las futuras consecuencias indeseables que son capaces de generar nuestros sistemas tecnológicos, o bien una emoción que nos impide elaborar un juicio razonable y que nos vuelve aún más vulnerables a las amenazas de la técnica.

\section{El catastrofismo racionalista de Jean Pierre Dupuy}

Jean Pierre Dupuy ha dedicado varios trabajos a reflexionar sobre las catástrofes en los que aborda el problema de los accidentes tecnológicos desde una perspectiva conceptual que afecta al núcleo de la concepción metafísica de nuestro mundo (Dupuy, 2002; 2005). Su punto de partida es el reconocimiento de que vivimos en una época de catástrofes que constituyen una amenaza para la supervivencia de la especie, lo que debería hacer replantearnos nuestros fundamentos éticos y metafísicos. Esta tesis continúa y reactualiza la defendida por Hans Jonas (1995), quien buscó un principio moral que sirviera para limitar un creciente poder tecnológico que ponía en peligro por primera vez la existencia de la vida humana en la tierra - al menos tal como la hemos conocido hasta ahora-. Los ecos de Günther Anders e Ivan Illich también son evidentes. Dupuy coincide con ambos en la tesis que de que el aumento de nuestras capacidades técnicas ha generado en la sociedad moderna una actitud de hybris, prepotencia y ceguera moral que nos impide practicar una forma de vida que imponga límites al poder técnico acaparado. Para el primero, la ceguera ante el inminente apocalipsis al que empuja la prosecución de determinados actos tecnológicos es causada por lo que denominó "desfase prometeico", esto es, la incapacidad de imaginar los devastadores efectos que tienen nuestras acciones. "[...] podemos producir más de lo que somos capaces de representarnos; el hecho de que los efectos resultantes de los instrumentos que nosotros mismos hemos producido son tan grandes que ya no estamos preparados para representárnoslos (Anders, 2011, 256).

En cambio, para Illich, de quien Dupuy fue colaborador, el origen de la bybris tecnológica reside en otro tipo de ceguera, consistente en no ser capaz de ver que el éxito de muchos de nuestros sistemas tecnológicos los vuelve ineficientes y causan más problemas que beneficios. Para Illich $(1975,1978)$, la incapacidad de comprender que muchas tecnologías se han vuelto no sólo ineficientes, sino peligrosas, sigue arrastrando a la sociedad a un uso desmesurado de éstas que puede llevar al colapso.

Dupuy, quien comparte el carácter pesimista de ambos autores, procede a hacer un diagnóstico de la situación actual que le lleva a analizar la importancia que se ha otorgado a la noción de riesgo como elemento teórico para entender y gestionar los peligros de la tecnología. El problema de nuestra época, a su juicio, es que pretendemos amortiguar las consecuencias indeseables de nuestras acciones técnicas, que se expresarían como daños irreversibles para el futuro humano y del planeta, mediante el uso de un concepto surgido de teorías matemáticas que 
trataban de calcular las probabilidades de ganar en distintos juegos de azar. Por ello, y para no seguir jugando "al poker con el clima futuro de la Tierra" (Dupuy, 2002, 19), sería necesario poner en cuestión los presupuestos del cálculo experto que prescribe una traducción de los valores que atribuimos a aquello que puede resultar dañado a unidades monetarias. Esto no sólo por la arbitrariedad que constituye la equiparación entre valor y precio, sino porque el pensamiento probabilístico, propio de los expertos, impide tomar realmente en serio las amenazas debido a que en él se mezclan dos lógicas incompatibles. (Dupuy, 2005, 23) Por un lado, la del cálculo económico de los evaluadores y la de la eficiencia como principio rector de la tecnología; por otro, la de la incertidumbre inherente a toda acción que incida en un entorno complejo y la de la irreversibilidad de los daños que pueden ser provocados al ecosistema. ¿Cómo podría - se pregunta Dupuyla racionalidad propia de los especialistas afrontar una situación de amenaza que está transida por la incertidumbre? La respuesta pone al descubierto un acto de prestidigitación epistemológica, ya que la estrategia de gestores y evaluadores profesionales reside en transformar situaciones de incertidumbre en fenómenos susceptibles de control y cálculo, es decir, en riesgo. Dicha transfiguración artificial de la incertidumbre en riesgo implica evadir el hecho de que no es posible asignar probabilidades a eventos que, o bien sólo se producen una sola vez, o cuyas frecuencias son inobservables. Este método, además de resultar artificial y arbitrario, es inútil para comprender el impacto real de nuestras actividades en el ecosistema, pues en la mayoría de los casos no existen frecuencias observables y por tanto no se puede disponer de datos estadísticos. Ante estas situaciones de incertidumbre, los expertos, en vez de reconocer sus propias limitaciones cognitivas, prefieren asignar probabilidades de manera subjetiva. Sin esta asignación, las consecuencias de nuestras acciones seguirían percibiéndose y manejándose como lo que realmente son: incertidumbres.

El problema de esta atribución subjetiva de probabilidades es doble. En primer lugar, modifica la manera de abordar las amenazas, pues mientras la precaución constituiría la actitud adecuada para gestionar una situación de incertidumbre, la prevención lo sería para afrontar posibles hechos de los que se conoce su probabilidad de ocurrencia. Con la transformación arbitraria de la incertidumbre en riesgo, cualquier medida precautoria se disuelve en herramienta de prevención. El segundo problema, que no es considerado por Dupuy, se debe a que la asignación subjetiva de probabilidades es llevada a cabo por una comunidad de expertos. Esto hace que, de una situación de incertidumbre, en la que la ignorancia respecto a la probabilidad de ocurrencia de hechos catastróficos se reparte entre toda la población independientemente de los conocimientos que posea cada cual, se pase a una situación de riesgo establecida por los mismos expertos que se han encargado de asignar probabilidades. Con la consecuencia de que si la aceptabilidad del riesgo se basa en el cálculo de probabilidades en vez de en el potencial catastrófico de la tecnología, es la propia comunidad experta la que construye el terreno teórico que luego legitimará su estatus decisorio para gestio- 
nar ese riesgo. La elección metodológica de la evaluación de riesgos, por tanto, desemboca en estrategias preventivas en vez de precautorias y oculta la verdadera solución: desprenderse de un tipo de racionalidad que ha demostrado su incapacidad para manejar los problemas que ella misma ha creado.

Para Dupuy $(2005,101)$ además, tomar en cuenta los cálculos probabilísticos para gestionar situaciones de potencial catastrófico implicaría caer en la misma lógica burocrática que Hannah Arendt (1994) detectó en una de las mayores atrocidades del s. XX. La filósofa, corresponsal en el juicio de Eichmann, entendió que el encargado de llevar a los prisioneros del totalitarismo nacionalsocialista a los campos de exterminio no mostraba un exceso de maldad, sino una falta radical de pensamiento que se expresaba mediante justificaciones que apelaban a la necesaria subordinación de sus actos respecto a una empresa cuyos objetivos y métodos no eran cuestionables. Con esta controvertida comparación, Dupuy pone de manifiesto que la catástrofe que se cierne sobre la sociedad contemporánea tiene el mismo carácter que una de las mayores aberraciones político-morales del s. XX, pues la visión actual del apocalipsis no se sustenta en la creencia de que la humanidad se pueda autodestruir intencionadamente (por ejemplo, haciendo un uso bélico de su poder tecnológico), sino por la ignorancia de la sociedad respecto a las consecuencias de una utilización pacífica de la tecnología que, o bien causa accidentes catastróficos que suponen una disrupción radical en los acontecimientos cotidianos, o va afectando lenta pero continuamente la salud y el medioambiente por la emisión de contaminantes y residuos tóxicos. Y todo ello legitimado por métodos de evaluación de riesgos que no tienen la capacidad de hacer frente a la magnitud e irreversibilidad de los dańos que pueden ser causados.

Una vez hecho el diagnóstico de la situación y desarrollada la crítica a la evaluación experta del riesgo, Dupuy analiza algunas estrategias utilizadas para evitar las consecuencias negativas de la tecnología: la del riesgo cero, la del peor escenario y la de la inversión de la carga de la prueba. La primera de ellas, que recomienda elegir cursos de acción completamente seguros, resultaría inadecuada una vez aceptado que en un mundo donde rigen la incertidumbre y la controversia científica no existe posibilidad de atribuir un riesgo nulo a cualquiera de las acciones que decidamos llevar a cabo. La falta de certeza nos impide establecer una predicción suficientemente confiable respecto a si alguna de las medidas de prevención que pudiéramos llevar a cabo va a evitar una catástrofe futura. Por otra parte, la medida de la carga de la prueba, por la que se insta a quienes pretenden implementar una tecnología a que demuestren su inocuidad, es acreedora del problema de los métodos de verificación seńalado por Popper (1991, 238). Una teoría no puede ser verificable debido a que la existencia de muchos casos observados empíricamente que concuerden con las predicciones no asegura que la siguiente observación no pueda ser un la de un evento falsador. Por tanto, si alguien intentara, por ejemplo, defender la inocuidad de un determinado producto químico, vería limitada su pretensión, entre otros motivos, por el número de 
casos que hayan sido estudiados. En cambio, la hipótesis de la inocuidad podría ser falsada en cuanto un solo sujeto mostrara cualquier nivel de dańo atribuido a la ingesta o exposición a la sustancia objeto de estudio. A pesar de este problema, Dupuy admite que, en caso de sospechar la ocurrencia de dańos graves o irreversibles, sería preferible equivocarse por la imputación de nocividad en un falso positivo en lugar de por un falso negativo que provocara dańos. En este sentido, la única estrategia sensata pasaría por llevar a cabo estudios que aseguren un nivel suficiente de inocuidad aun cuando sea de manera aproximada. Es decir, seguir con la inversión de la carga de la prueba exigiendo conclusiones sobre la inocuidad que no pretendan ser absolutas.

Sin embargo, donde se manifiesta realmente la originalidad de la propuesta catastrofista de Dupuy es en la crítica que lanza a la tesis del peor de los escenarios por la cual se recomienda evitar la peor de las consecuencias que pudieran derivarse de un determinado curso de acción técnica. Dupuy señala que regirse por la idea de que debemos evitar las peores posibles consecuencias de nuestras acciones no es una alternativa lo suficientemente fuerte para erigirse en un fundamento ético sólido y a la altura de los tiempos de catástrofe que vivimos. Esto porque, mientras la estrategia de evitar el peor posible escenario se basa en un modelo que concibe un árbol de posibilidades y probabilidades, a la perspectiva catastrofista le resulta insuficiente creer que algo se pueda producir. Por tanto, la alternativa que se propone para hacer realmente efectivo nuestro abordaje de los problemas que entraña la tecnología es un catastrofismo racional o "éclairé" basado en la idea de que hay que actuar como si se supiera con certeza que el acontecimiento catastrófico va a suceder. Así, dándole la vuelta a la expresión bergsoniana de que todo es a la vez probable e imposible, Dupuy desarrolla una tesis metafísica de carácter paradójico que permite pensar un evento como si fuera necesario y a la vez improbable:

Antes de que la guerra estallase, ésta le parecía a Bergson como probable a la vez que imposible: idea compleja y contradictoria que persistió hasta el día fatal. La metafísica que propongo como fundamento de un tipo de prudencia adaptado a los tiempos de catástrofes no es menos compleja, aunque creo poder demostrar que no es contradictoria. Esta consiste en proyectar un tiempo posterior a la catástrofe y ver a ésta retrospectivamente como un evento a la vez necesario improbable. (Dupuy, 2002, 87)

El catastrofismo racional reactualiza así la heurística del miedo, una idea desarrollada por Jonas para sustentar un principio de responsabilidad que afirma que debemos obrar de tal forma que los efectos de nuestras acciones sean compatibles con la permanencia de una vida humana auténtica en la tierra. La subordinación de las decisiones a este principio tiene el objetivo de afrontar las amenazas tecnológicas para la supervivencia de la especie. Sin embargo, esta estrategia no sugiere 
dejarse llevar por un sentimiento de pavor ante la destrucción tecnológica; ya que se trata más bien de una emoción simulada de miedo, racionalmente establecida, que nos sirve para poner en marcha acciones orientadas a la supervivencia en tiempos en los que la vida de las generaciones futuras no está asegurada. En este sentido, la guía de acción que ofrece la heurística del miedo es tomar en serio una futura extinción y detener empresas tecnológicas sospechosas de poder provocarla. Dupuy, entonces, radicaliza la idea de Jonas despojándola de cualquier residuo posibilista, y sostiene que la única vía para hacer frente a un horizonte catastrófico es construir una ficción metafísica del tiempo en la que tenga cabida la fatalidad. La heurística del miedo, integrada a una nueva metafísica, permitirá fundar la ética del porvenir a la que nos obliga ese desajuste prometeico de nuestras capacidades que nos impide imaginar y prever todo el daño capaz de causar nuestra cada vez más poderosa competencia técnica.

Las características de este nuevo horizonte temporal son trazadas en contraposición a la idea tradicional que sostiene un concepto lineal del tiempo en el que el pasado se considera un ámbito fijo e irreparable y el futuro un horizonte de posibilidades abiertas. La concepción ortodoxa del tiempo, la propia del tiempo de la historia, es presupuesto por todas las acciones que tienen la intención de ser preventivas, pues el evento que se quiere prevenir es un acontecimiento posible que, en tanto no ha acontecido aún, podría no realizarse. El problema es que esta metafísica no nos capacita para creer de veras en la urgencia de actuar para detener la catástrofe. En tanto que ésta se perciba como simple posibilidad, se legitiman medidas de regulación orientadas a la no ocurrencia. Sin embargo, el carácter de incertidumbre irreductible de nuestras prácticas y su impacto en el entorno hace que sea imposible saber de antemano si las medidas correctivas serán eficaces. La complejidad de los ecosistemas, sumada a la de los sistemas técnicos que se acoplan a ellos en un sistema híbrido en el que ocurren interacciones cada vez más imprevisibles cercena cualquier posibilidad preventiva que pretenda evitar con seguridad el acontecimiento catastrófico. Por ello se torna necesario pasar del tiempo de la historia, ese tiempo donde el presente es inmutable y el futuro un abanico de posibilidades que se excluyen entre sí, a una nueva concepción del tiempo que no esté sometida a la linealidad y la irreversibilidad. En este nuevo tiempo, denominado el tiempo del proyecto (Dupuy, 2002, 201), la catástrofe, entendida como una fatalidad ya realizada, permite observar el presente desde el futuro para evitar el propio acontecimiento desde el que se mira. Para ejemplificar esta idea podría recordarse la campańa que lanzó con gran éxito retórico y mediático Greenpeace en 2009 para advertirnos sobre los peligros del cambio climático. En ella se presentaron carteles con imágenes de varios líderes mundiales envejecidos simulando estar en el ańo 2020 y pidiendo disculpas por no haber actuado contra el cambio climático. La campaña, al igual que el catastrofismo de Dupuy, invita a pensar el tiempo como un bucle donde el futuro 
tiene la capacidad de revertir el pasado para no acontecer ${ }^{2}$. En esta nueva concepción del tiempo, Hans Jonas vuelve a ser la referencia. Para Dupuy la función de Jonas fue la de ejercer como un profeta del infortunio que advierte de la fatalidad sabiendo que su mala nueva era un destino cuya realización dependía de la aceptación o el rechazo social de la profecía que estaba profiriendo. Las advertencias del profeta se hacen públicas precisamente para evitar que la profecía se cumpla. La fundación del catastrofismo sobre el tiempo del proyecto, un tiempo cíclico que se sitúa en la contemplación de un accidente venidero para evitarlo, depende de la figura del profeta para transformar nuestras políticas de prevención basadas en el riesgo en decisiones auténticamente prudentes frente a la fatalidad.

En definitiva, lo que confiere más fuerza argumental al catastrofismo racional es la idea de que no se puede actuar como si estuviéramos instalados en condiciones de riesgo, cuando realmente son de incertidumbre. Y puesto que la estrategia de asignación subjetiva de probabilidades encubre la verdadera situación de incapacidad previsora, la única solución sería hacernos cargo de la propia ignorancia y actuar como si la catástrofe fuera un destino. Sólo de este modo la humanidad podría actuar de una forma verdaderamente prudencial. Sin embargo, su solución adolece de tres problemas. En primer lugar, el tiempo del proyecto constituye una estrategia que pretende transformar una situación de incertidumbre real en un imaginario contexto determinista donde el acontecimiento futuro se vislumbra como algo que ocurrirá necesariamente. Esto, sin embargo, es susceptible de un reproche similar al que Dupuy hace a los expertos. Si es un error transformar la incertidumbre en riesgo asignando probabilidades a las posibles consecuencias derivadas de los distintos cursos de acción, no parece razonable convertirla en total certidumbre sobre el futuro. Dupuy justifica este movimiento alegando que actuar pensando que el peor escenario va a acontecer nos proporciona un recurso eficaz para evitar que suceda. Sin embargo, esta transformación de la incertidumbre en certeza podría servir para adoptar medidas que pretenden evitar un escenario que quizá no se produciría nunca, invisibilizando otras posibilidades, algunas de las cuales sí podrían ocurrir en el futuro. Por tanto, fijar la atención en el peor escenario y concebirlo como necesario, supone, además de evadir la incertidumbre, ocultar otras posibilidades que son susceptibles de materializarse provocando importantes daños. En este sentido, el uso de la noción de riesgo y la asignación de probabilidades, aun cuando constituyan recursos limitados para afrontar situaciones de incertidumbre, ponen en pantalla una variedad de posibles consecuencias que permitiría tomar decisiones mejor informadas.

\footnotetext{
${ }^{2}$ La novela Ruido de Fondo (DeLillo, 1994) presenta una situación ficticia que podría comprenderse en el marco del tiempo del proyecto descrito por Dupuy. En la novela se produce un escape tóxico y una de las consecuencias de la exposición a la nube contaminada es la aparición de situaciones de deja vú. La explicación de este fenómeno en la metafísica catastrofista no sería otro que se tiene la sensación de haber vivido ya ese acontecimiento de intoxicación porque el futuro era algo ya acontecido que no se había tratado de evitar.
} 
Por otra parte, la propuesta de Dupuy cercena toda posibilidad de gestión democrática de la incertidumbre. Ninguna deliberación llevada a cabo mediante mecanismos democráticos aseguraría tomar una decisión que evite la fatalidad. Al igual que para Jonas, en Dupuy la solución parece pasar por paralizar cursos de acción tecnológicos sin tener en cuenta las opiniones ciudadanas ni las expertas. La fundamentación racional del catastrofismo legitimaría por sí sola esta decisión. El filósofo, en condición de tal, se atribuye este estatus y sólo tendría que hacer pública la mala nueva. Como el sabio de Platón que ha accedido a la luz de las Formas y vuelve para educar a quien sólo contempla las sombras de la caverna, el filósofo tendría la misión de ejercer de profeta del advenimiento fatal. Con la diferencia de que la inteligibilidad del mundo a que llega el raciocinio filosófico de Dupuy no es una esfera habitada por Formas, sino por un cúmulo de escenas futuras de accidentes, catástrofes y destrucción.

El tercer problema del racionalismo éclairé es que, al asumir la heurística de Jonas, defiende una estrategia de construcción racionalista del miedo que anula el potencial que poseen las verdaderas emociones públicas. El miedo real no se genera tras una reflexión en la que se concluye la conveniencia de tenerlo para evitar posibles catástrofes. En este sentido Dupuy parece olvidar que no se trata de que se deba sentir miedo para evitar la pérdida que ocasionaría un dańo, sino que se teme porque se tiene la creencia de que algo valioso puede ser dañado. Es el verdadero temor, y no la construcción racionalista del miedo, lo que nos permite saber cuáles son las cosas importantes que deberíamos proteger. Por eso, la heurística del miedo, aunque se tome en serio los peligros que se ciernen sobre nosotros, resultaría menos eficaz para evitar daños que una expresión genuina del miedo. En definitiva, el elitismo del catastrofismo racionalista no aseguraría decisiones prudentes ni legítimas.

\section{Accidente y miedo en Paul Virilio}

El siguiente análisis sobre el carácter catastrófico de nuestra época es el de Paul Virilio, arquitecto y filósofo que ha abordado el fenómeno de la aceleración de los procesos de desarrollo tecnológico y sus implicaciones sociales y políticas (Virilio, 2006). En sus últimas obras, Virilio se ha centrado en los accidentes tecnológicos y el miedo que éstos provocan en las sociedades contemporáneas. Sus tesis no son menos originales que las de Jean Pierre Dupuy. Al igual que éste, es sensible a las consecuencias más perniciosas de algunos de los sistemas técnicos que configuran nuestra vida social. Sin embargo, también desconfía del miedo colectivo que la tecnología causa en la ciudadanía. Su análisis se instala en esta tensión: ¿Cómo es posible ser crítico con la tecnología por sus efectos nocivos y a la vez repudiar el miedo que éstos generan? Para tratar de contestar esta pregunta, Virilio parte de la idea de que la sociedad contemporánea alberga tal cantidad de hechos disruptivos catastróficos que se impone la necesidad de seguir un principio de responsabilidad que debería derivar de una reflexión sosegada de 
los accidentes. Esta invocación a la calma se explica porque la sociedad, a través de los medios de comunicación de masas, está expuesta a un flujo constante de imágenes de catástrofes y accidentes que, más que generar actitudes proclives a la prevención, provocan en realidad un miedo irracional que facilita la manipulación. El terrorismo, las pandemias, los accidentes, las sospechas de nocividad de algunos alimentos o la toxicidad de los vertidos industriales conforman el día a día de los teleciudadanos en los que nos hemos convertido y van creando una atmósfera de aversión a todo cuanto nos rodea. El miedo, por tanto, ha dejado de estar localizado en algún hecho concreto y esporádico y se ha transformado en pánico, un sentimiento que constituye el clima normal de la ciudadanía y que se desborda hacia todas las esferas de la vida. La tecnología (con sus consecuencias indeseables y su potencial bélico); sumada a la nueva dinámica social (que disminuye la fuerza vinculante de la familia y la condición de clase) han colocado al miedo y la inseguridad en el centro de la escena sociopolítica contemporánea. Sin embargo, la propagación de estos temores no ayudaría a evitar las verdaderas catástrofes, pues a juicio de Virilio el problema reside precisamente en que la reflexión filosófica -y en esto Jonas sería un ejemplo-ha asumido la idea de que el miedo es una emoción imprescindible para frenar el rumbo de los proyectos tecnológicos de los que se sospecha que pueden ocasionar daños de una magnitud considerable. En este sentido, si el temor ha sido considerado tradicionalmente como una emoción de la que había que desprenderse para llegar a una mayoría de edad ilustrada, ahora se comprende como un elemento necesario para salvaguardarnos de los peligros que acechan. El miedo, en definitiva, ha devenido una emoción celebrada por la filosofía que sirve de guía para sortear las constantes amenazas y dirigir nuestras acciones de manera cautelosa. Las siguientes palabras de Günther Anders ejemplifican esta apropiación filosófica del miedo:

[...] en comparación con la cantidad de miedo que nos convendría y que propiamente deberíamos sentir, somos simplemente analfabetos del miedo. Y si hay que aplicar un lema a nuestra época, lo mejor sería llamarla la época para la incapacidad para tener miedo (Anders, 2011, 255)

Virilio, respecto a esta cuestión, considera que quienes ven en la generación de miedo una virtud no aportan una buena justificación teórica. Por un lado, porque no ofrecen una explicación sobre las causas verdaderas del miedo, con lo cual tampoco están en condiciones de ofrecer soluciones eficaces; por otro, porque ese miedo se dirige a eventos particulares que se proyectan con el propósito de manipular a la sociedad, dejando sin comprender los efectos más problemáticos del desarrollo tecnológico. Para solucionar este déficit teórico, Virilio trata de dar una explicación que origine preocupación por lo que realmente merece ser temido y evite los temores recurrentes que no deberíamos tener. La base de esta explicación parte de la constatación de que la tecnología modifica el ritmo y la velocidad del mundo. Esto ha sucedido con el desarrollo de sistemas de transpor- 
te cada vez más veloces que han transformado la estética, estructura y funcionamiento de las ciudades; y con la aparición de nuevas tecnologías de la información capaces de transmitir imágenes y sonidos a todos los confines del mundo de manera simultánea. La tecnológica ha adquirido tres características que eran propias de la divinidad: la ubicuidad, el poder y la instantaneidad (Virilio, 2012, 51) La reducción de horas que uno tarda en llegar a las antípodas del planeta, la visualización de hechos que ocurren a miles de kilómetros de distancia o la interacción simultánea con distintos lugares, ha supuesto un empequeñecimiento del planeta y una modificación de nuestra comprensión espacio-temporal.

La ruptura de las fronteras, lejos de ser valorada como una ventaja, debería constituir para Virilio un motivo de preocupación, ya que la estrechez del espacio genera desasosiego ante la pérdida de magnificencia de la Tierra. Con el agravante de que la comunicación a distancia ha hecho perder a los individuos el contacto real con el otro convirtiéndonos a todos en seres corporalmente desapegados que pasan la mayor parte de su tiempo en un mundo fantasmagórico y virtual (Virilio, 1997, 50) Es cierto que este diagnóstico pesimista, si bien es sensible a muchas patologías y problemas que se manifiestan con las nuevas formas de interacción social, no reconoce el potencial de vinculación que posee la red al permitir de manera sencilla y rápida articular comunicaciones entre individuos con intereses sociales, culturales o políticos similares que luego se encuentran y tienen incidencia en el mundo real. No obstante, omitir este potencial político le permite afirmar que en la época de las relaciones virtuales se está produciendo una pérdida del sentido de la polis debido a que los vínculos interpersonales están mediados por escenas propagadas por las tecnologías de la información que provocan reacciones emocionales perjudiciales para los debates democráticos. En este sentido, para Virilio la velocidad impuesta por la tecnología hace ingenua cualquier propuesta de mejora en los procesos de toma de decisiones democráticas que esté basada en el uso de los medios de comunicación. Esto porque la tiranía contemporánea se expresa en el tiempo acelerado en que vivimos y que es producto del ritmo vertiginoso con que se propaga el cúmulo de informaciones que recibimos. El ciudadano, voluntariamente sumergido en un ámbito virtual, recibe tal cantidad de datos e informaciones que se torna difícil su procesamiento racional. Este hecho, junto a la pérdida de contacto con otros en los espacios físicos de la polis, pone en peligro la democracia, ya que ésta requiere de procesos de vinculación social deliberativos donde se expongan una pluralidad de puntos de vista razonados. Hemos entrado, por tanto, en la segunda etapa de la disolución de la comunidad política provocada por la comunicación de masas. En la primera etapa, con la entrada en escena de la prensa y la radio, lo que se proyecta es la palabra y el discurso. Entonces la ciudadanía pudo recibir información sobre diferentes eventos del mundo que de otra forma no se hubieran conocido aun cuando estuviera mediada por la interpretación que de ellos hiciera el canal o la editorial de turno. Esta situación transformó el espacio político contemporáneo. Por un lado, se abrieron canales de información que dieron impulso a un ideal 
republicano basado en la idea de que la ciudadanía debe tener conocimiento sobre diferentes asuntos públicos de relevancia. Por otro, con la proyección de la interpretación de las líneas editoriales hegemónicas, se produjo una homogeneización y polarización de las opiniones. El hecho de que la mayor parte de la ciudadanía desayune con el mismo periódico y coma viendo el mismo noticiero provoca una sincronicidad de las opiniones que es aprovechada para dirigir las voluntades políticas. Esta etapa, sin embargo, ha quedado actualmente desfasada con el desarrollo de las tecnologías de la información y la comunicación. Esta nueva fase en la que estamos inmersos constituye, a juicio de Virilio, una fase postrepublicana más expuesta a los peligros del condicionamiento conductual. La televisión, aún predominante como medio de entretenimiento e información, ya no está orientada exclusivamente a la proyección de discursos que aumenten el proselitismo político. El objetivo ahora es el de transmitir una gran cantidad de imágenes catastróficas para homogeneizar los afectos. El televidente, sometido a una vorágine de escenas de horror repetidas hasta la saciedad, reacciona ante ellas de una forma predominantemente emocional. Y como los medios tienen la capacidad de transmitir estas imágenes de manera simultánea a todo el planeta, se logra una sincronicidad mundial de las emociones. Para sostener esta tesis, Virilio $(2012,55)$ recuerda el tratamiento que se le dan a algunas acciones terroristas. Por ejemplo, después del atentado contra las Torres Gemelas, el mundo estuvo expuesto a unas imágenes que se repetían de manera ininterrumpida: la del avión estrellándose contra el edificio que pocos minutos después colapsaba. Esta escena ineludible del imaginario colectivo de la contemporaneidad absorbió todas las miradas y generó una comunidad de emociones sincronizadas que propiciaron el respaldo popular para la invasión de Irak. Lo que se quiere mostrar con ejemplos como éste es que la reiteración de imágenes con tintes apocalípticos instala a la sociedad en el mismo universo de emotividad. Y si bien es cierto que esta situación puede resultar provechosa, como cuando la visión de una catástrofe pone en marcha un auténtico movimiento de solidaridad hacia las víctimas, las oportunidades que se abren para el control poblacional deberían hacer considerar con más profundidad el asunto. La modificación de la voluntad colectiva mediante la proyección de una catástrofe se logra gracias a mecanismos de administración del miedo:

Lo que creo es que, ante todo, nos enfrentamos a una situación de emergencia provocada por un verdadero delirio colectivo que está, a su vez, reforzado por la sincronización de las emociones, es decir, por la súbita globalización de los afectos en tiempo real que golpea a la humanidad en el mismo instante. Y este ocurre en el nombre del Progreso. Emergency exit: estamos en la era del pánico generalizado. (Virilio, 2012, 92) 
Con la administración del miedo por los medios de comunicación, la sociedad descubre que hay buenos motivos para sentir aversión a ciertas tecnologías, pero queda incapacitada para tomar medidas realmente efectivas para erradicar las causas que la provocan. La catástrofe, expuesta por las tecnologías de la comunicación, oculta el hecho de que es la misma naturaleza de la tecnología la que provoca la catástrofe. Los medios de comunicación siguen la misma lógica que el resto de tecnologías por las que se siente aversión. Como los sistemas de transporte transcontinentales, su incidencia en el mundo tiene alcance universal. Además, a la presentación mediática de la catástrofe le subyace una lógica de afirmación del progreso que impide siquiera concebir que éste sea el origen del problema. La emotiva reacción inicial a la secuencia de catástrofes proyectadas limita las posibilidades de una crítica seria porque siempre se buscan soluciones técnicas para resolver los problemas. En definitiva, lo que la proliferación de imágenes y la reacción emotiva e irreflexiva ante éstas impide comprender es que se está fomentando la misma lógica inherente a la idea de progreso para mitigar las consecuencias perniciosas del crecimiento, el desarrollo y la eficacia técnica.

Una vez diagnosticado el verdadero problema, Virilio recomienda no dejarse avasallar por la exposición continua de imágenes como medida para evitar ese sentimiento de pánico generalizado sincronizado que es aprovechado por las diferentes instancias de poder para dirigir las conductas. Su propuesta para evitar este control psicopolítico es replantear el tema del accidente y colocarlo en el candelero de la reflexión social. De esta manera se explica que la obra teórica de Virilio haya sido acompañada de una exposición artística, presentada en la Foundation Cartier de París, en la que se presentaban diferentes imágenes de catástrofes industriales y tecnológicas. La primera duda que podría suscitar el hecho de poner en el centro de atención el tema del accidente a través de una especie de museo de los horrores es si no está haciendo precisamente aquello que se critica, es decir, mostrar a los ojos del público situaciones dramáticas que provocan reacciones emotivas poco propensas para salir de la situación de vulnerabilidad política y abandonar la ideología del progreso. Sin embargo, la diferencia entre la proyección mediática del horror tecnológico y la presentación museística del accidente parece sustancial. Al sacar la catástrofe de los medios de comunicación y colocarla en un espacio artístico y de reflexión se pretende evitar las reacciones inmediatas e impulsivas para, en su lugar, detonar un análisis sobre los horrores tecnológicos. El abordaje reflexivo del accidente serviría para hacer comprender que la naturaleza de la técnica es tal que con su aparición emerge de manera irrevocable el error. De esta forma, el miedo, que sólo consigue imprimir más velocidad a la tecnología en una huida hacia delante, dejaría su lugar a una crítica racional y sosegada de la tecnología que evidenciaría las causas reales de los accidentes.

La constatación de que a todo sistema tecnológico siempre le ha acompañado un tipo de accidente, y de que cuanto mayor ha sido el potencial técnico más cantidad de destrucción ha provocado, lleva a Virilio a pronosticar la inevitable 
irrupción de una fatalidad en ámbitos tecnológicos respecto a los cuales aún no hay evidencia, o al menos existe controversia, sobre su potencial destructivo. En este sentido, su tesis es igual de fatalista que la de Dupuy. Para ambos el mundo tecnológico parece ser percibido como una gran fábrica de catástrofes. Sin embargo, mientras Dupuy señala que la catástrofe va a acontecer precisamente por nuestra obtusa forma de tratar de evitarla, Virilio pone el acento en el hecho de que es el éxito y la aceleración de la tecnología lo que pone en marcha intervenciones con mayor capacidad de devastación. En este sentido, el acortamiento de las fronteras espaciales y la universalización de algunas líneas de acción tecnológica abrirían las puertas a un nuevo tipo de accidente, el accidente total o integral (Virilio, 2005, p.59) Ya no se trataría de que los efectos no deseados de un sistema técnico se desborden a algunos ámbitos contiguos, como cuando se vierten residuos de una central química que contaminan un acuífero cercano, sino de que los efectos provocados por sistemas conectados a escala planetaria afectarían a todo la humanidad sin distinciones de nacionalidad. Para Virilio, por tanto, el alcance global de sistemas cada vez más interconectados entre sí lleva aparejado un próximo accidente fatal con consecuencias de elevada magnitud. Ante esta perspectiva fatalista, la solución no puede pasar por desarrollar tecnologías más eficientes, ya que así sólo se continuaría en la línea de legitimación de una idea de progreso orientada a la generación de innovaciones que logren paliar los efectos no deseados de la tecnología usada hasta el momento. Por el contrario, si se logra comprender que cada sistema trae aparejado un nuevo tipo de catástrofe y que la velocidad y el estrechamiento del mundo entraña la posibilidad de un accidente total, la actitud razonable y prudente sería la de intentar devolverle el ritmo al mundo poniendo freno al ímpetu desarrollista de la sociedad contemporánea.

Respecto a la consideración de los riesgos, la posición de Virilio pareciera coincidir con la de aquellos que muestran aversión hacia la tecnología; sin embargo, sus opiniones sobre la propagación del miedo lo acercan a algunas opiniones recurrentes de los expertos en evaluación de riesgos. Con estos últimos coincide en señalar que la sobrecarga de imágenes de catástrofes provoca una reacción emotiva que impide una interpretación racional de los verdaderos peligros. En este sentido, parte de su discurso filosófico sobre el miedo no hace más que recordar la importancia que tiene un fenómeno ampliamente analizado por psicólogos sociales especializados en la percepción y evaluación pública del riesgo, el de la heurística de la disponibilidad (Tersvy y Kahneman, 1974; Slovic, 2000, p.106-107; Sunstein, 2006, 13,). Este fenómeno se produce cuando se tiene una aceptabilidad baja y se atribuye una probabilidad mayor a un riesgo que está implicado en situaciones sobre las que tenemos algún recuerdo. La heurística de la disponibilidad es detonada por la importancia otorgada a las experiencias pasadas o por la proyección mediática de catástrofes, accidentes o enfermedades. Cuando la televisión transmite las imágenes de una explosión en una refinería petroquímica o la evacuación masiva producida por un accidente como el de Fukushima, la percepción social de los riesgos de sistemas tecnológicos similares 
sufre un significativo aumento durante los días o meses siguientes, que va diluyéndose conforme pasa el tiempo. La disponibilidad, por tanto, está vinculada a los medios de comunicación. Así, si existen algunas causas de muerte con gran cobertura mediática, éstas se tienden a sobreestimar. Al contrario, si algunas enfermedades o causas de muerte no son publicitadas, se tenderá a subestimar la probabilidad de su ocurrencia. La heurística de la disponibilidad está conectada con otros fenómenos psicosociales. Uno de ellos es el de la cascada de la disponibilidad (Kuran y Sunstein, 1999, 683-768), consistente en la replicación de una noticia sobre alguna tragedia que va adquiriendo cada vez mayor nivel de dramatismo e importancia para la opinión pública. De esta forma, la noticia de un evento, aunque sea estadísticamente insignificante, puede ir condicionando la opinión pública en función del número de repeticiones y el grado de dramatismo con la que sea proyectada. Estas situaciones hacen que las opiniones y preferencias de la gente sean condicionadas por noticias o rumores que se propagan como un reguero de pólvora. Además, si los recuerdos son vívidos y ricos en detalles, la probabilidad asignada a la ocurrencia de un evento similar será mucho mayor que si los recuerdos no vienen acompañados de imágenes impactantes.

Como puede apreciarse, las tesis de Virilio son congruentes con las conclusiones extraídas de los estudios sobre percepción de riesgo. Sin embargo, sus propósitos difieren radicalmente de aquellos que esgrimen estos fenómenos psicológicos para criticar la falta de confianza que muestra la sociedad en la evaluación de los expertos. Porque si de lo que se trata es de mitigar los temores causados por la sobrecarga de imágenes, no es para avalar una evaluación experta del riesgo que prescinda de la ciudadanía y esté basada en la cuantificación, la estadística y el cálculo probabilístico; sino para ejercer una crítica al desarrollo tecnológico y fomentar un pensamiento crítico-filosófico sobre la catástrofe que vaya a la raíz del problema:

Ahora bien, creo que no podemos tratar nuestro porvenir ni nuestra historia en términos exclusivamente cuantitativos, ya que, cuando actuamos así, en cierto sentido estamos abandonando la historia. Si nos limitamos a examinar los problemas desde un punto de vista cuantitativo, nos vemos paradójicamente conducidos a vislumbrar soluciones que rompen de manera radical, y esta vez cualitativamente, con nuestra verdadera vida. (Virilio, 2012, 75)

La racionalidad de los expertos, por tanto, no estaría en condiciones de ofrecer soluciones para contender con el horizonte catastrófico que se elucubra con la velocidad impuesta por el desarrollo tecnológico, ya que la única manera de reducir el sentimiento de temor es ejerciendo una crítica a la idea de progreso que conduzca al freno del desarrollo. Sólo así se vislumbraría la posibilidad de que la sociedad deje de estar sometida al uso de tecnologías que estrechan los límites espaciotemporales y tome medidas eficaces para evitar la catástrofe. Estas 
tesis de Virilio sobre la catástrofe son sugerentes e invitan a pensar las consecuencias psicológicas y políticas generadas por la velocidad que imprime a la vida la tecnología contemporánea. Sin embargo, adolecen de problemas importantes. $\mathrm{Su}$ interés en desviar los miedos infundados hacia lo que realmente debe ser temido le impide reconocer que podría haber expresiones de temor genuinas hacia diferentes sistemas tecnológicos que no sólo no estuvieran afectadas por una sobrecarga emocional que deteriora el juicio, sino que podrían provenir de percepciones basadas en conocimientos y experiencias legítimas. Por otra parte, al igual que en el caso de Dupuy, su dictamen negativo hacia las evaluaciones expertas de riesgo le impide reconocer que son una vía limitada pero útil para tomar decisiones en materia tecnológica basadas en nuestro mejor conocimiento disponible. En definitiva, su obsesión por los problemas que genera la velocidad le lleva a prescindir de recursos valiosos, tanto en lo que respecta a la percepción pública del riesgo como a la evaluación experta, para evitar riesgos derivados de la tecnología.

\section{Conclusión}

El análisis que se ha llevado a cabo en este trabajo sobre las tesis desarrolladas por Virilio y Dupuy sobre el miedo, el riesgo, la catástrofe y los accidentes ha puesto de manifiesto algunas coincidencias y diferencias sustanciales. Entre las similitudes podemos destacar que ambos: 1) asumen una visión tecnofóbica que pone el foco de atención en las consecuencias indeseables de la tecnología; 2) comparten una estrategia teórica de corte escatológico que hace de la predicción apocalíptica un recurso imprescindible para tratar de evitar accidentes y catástrofes tecnológicos; 3) defienden un análisis crítico-racional no cuantitativo para interpretar el problema de los accidentes y poder concretar acciones regidas por la prudencia. Las diferencias, no obstante, también son profundas. Mientras que para Dupuy el medio más efectivo para evitar una futura catástrofe es adoptar la heurística del miedo, Virilio afirma que la velocidad de los procesos tecnológicos origina un miedo colectivo que, administrado para controlar a la población, no consigue frenar los sistemas de producción científica y aplicación técnica, sino que, por el contrario, acelera más su desarrollo. En este sentido, si para Dupuy, seguidor en esto de Jonas, la imagen del peor escenario (no posible, sino necesario) es la herramienta más poderosa para evitar los acontecimientos catastróficos, para Virilio el verdadero problema se crea por el exceso de miedo que origina la visualización mediática de la catástrofe. Por último, respecto a la noción del riesgo sus tesis también divergen, pues, aunque ambos desarrollen una crítica a las evaluaciones expertas, Dupuy no acepta como legítima ni útil la noción de riesgo y omite la posibilidad de una evaluación democrática para evitar futuros daños; mientras que Virilio añora una verdadera comunidad política que pueda afrontar el problema de la catástrofe sin estar afectada por miedos que desvían la atención de lo importante. Estas diferencias, no obstante, motivan a seguir pensando 
los problemas del mundo tecnológico y nos hacen sospechar que los conceptos de "democracia" y "miedo" deberían constituirse como los ejes que delimiten el marco de interpretación de una sociedad que se percibe a sí misma al borde de una inminente catástrofe.

\section{Referencias bibliográficas}

Adorno, Theodor y Max Horkheimer (1998). Dialéctica de la Ilustración. Madrid: Trotta.

Anders, Günther (2011). La obsolescencia del hombre, vol. 1. Valencia: Pre-Textos.

Arendt, H. (1994). Eichmann in Jerusalem: A report on the banality of evil. New York, N.Y., U.S.A: Penguin Books.

Carson, Rachel (1962). Silent Spring. Boston, Massachusetts: Houghton Mifflin Company.

DeLillo, Don (1994). Ruido de Fondo. Barcelona: Seix Barral.

Dupuy, Jean Pierre (2002). Pour un catastrophisme éclairé. Paris: Éditions du Seuil.

Dupuy, Jean Pierre (2005). Petite métaphysique des tsunamis. Paris: Éditions du Seuil.

Horkheimer, Max (2002). Crítica de la razón instrumental. Madrid: Trotta.

Illich, Ivan (1975). Némesis Médica. Barcelona: Barral Editores.

Illich, Ivan (1978). Energía y equidad. México D.F: Editorial Posada.

Jonas, Hans (1995). El principio de responsabilidad. Barcelona: Herder.

Kuran, Tim y Cass Sunstein. (1999). Availability Cascades and Risk Regulation. Stanford Law Review, 51(4), 683-768.

Mitcham, Carl (1998). ¿Qué es la filosofía de la tecnología? Barcelona: Anthropos.

Olivé, León y Ruy Pérez Tamayo (2011). Temas de ética y epistemología de la ciencia: diálogos entre un filósofo y un científico. México: Fondo Cultura Económica.

Popper, Karl (1991). Conjeturas y refutaciones. Barcelona: Paidós.

Slovic, Paul (2000). The perception of risk. Londres: Earthscan.

Sunstein, Cass (2006). Riesgo y razón: Seguridad, ley y ambiente. Buenos Aires: Katz. 
Tervsky, Amos y Daniel Kahneman (1974). Judgement under Uncertainty: Heuristics and Biases. Science, 185(4157), 1124-1131.

Virilio, Paul (1997). El cibermundo: la política de lo peor. Madrid: Cátedra.

Virilio, Paul (2005). El accidente original. Madrid: Amorrortu.

Virilio, Paul (2006). Speed and Politics. Los Ángeles: Semiotex(e).

Virilio, Paul (2012). La administración del miedo. Madrid: Pasos Perdidos. 
